\title{
Mulemba
}

Revista Angolana de Ciências Sociais

5 (10) | 2015

Angola 40 anos de independência: memória, identidades, cidadania e desenvolvimento

\section{Um desafio em busca de uma nova perspectiva global contra-hegemónica no campo da saúde}

\author{
José Octávio Serra Van-Dúnem
}

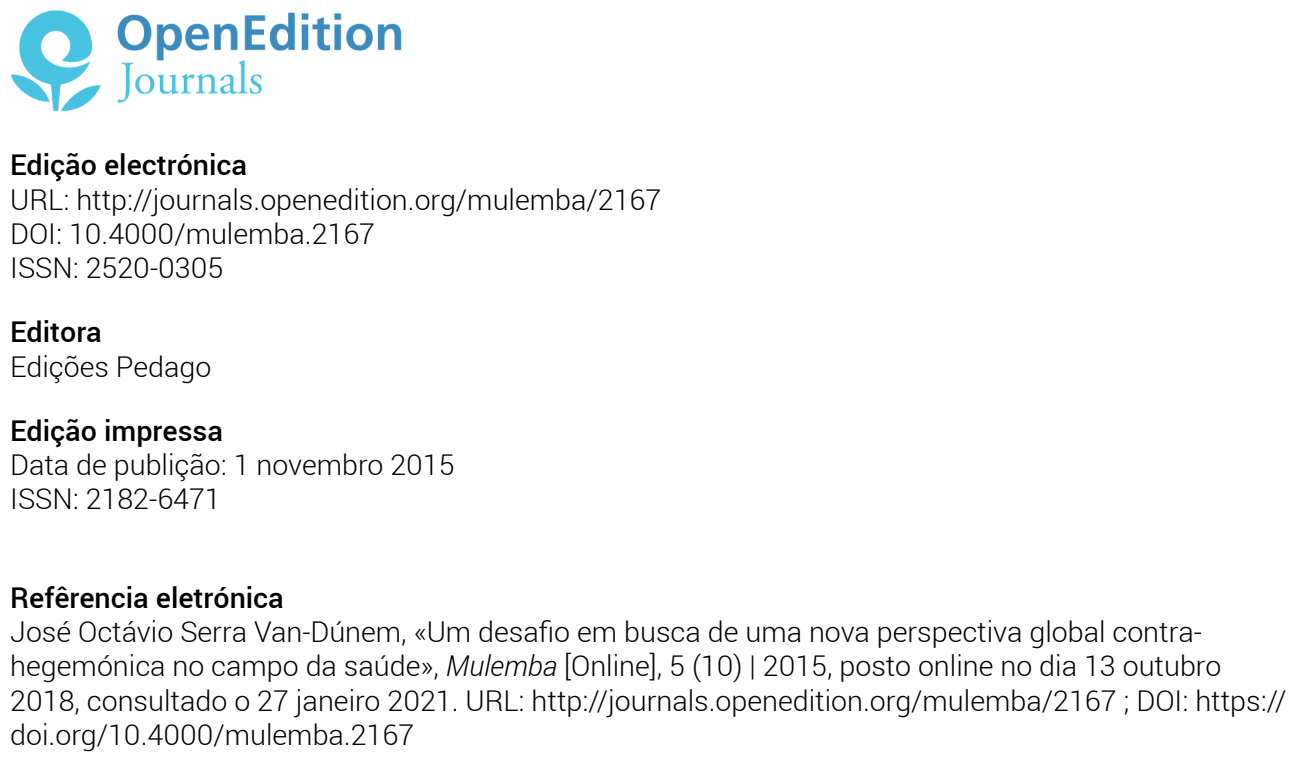

Tous droits réservés 


\title{
Um desafio em busca de uma nova perspectiva global contra-hegemónica no campo da saúde*
}

\author{
José Octávio Serra Van-Dúnem**
}

Começo por cumprimentar as autoridades académicas, religiosas e políticas, bem como os estudantes e demais convidados aqui presentes.

Agradeço o convite da professora, colega e amiga Doutora Fátima Viegas para vir aqui assumir tamanha responsabilidade junto deste selecto público, nesta casa do saber, a nossa Faculdade de Ciências Sociais (FCS) da Universidade Agostinho Neto (UAN) e ao seu Decano, meu colega e amigo Professor Víctor Kajibanga.

Apresentar um livro é sempre um desafio, porquanto temos que mergulhar na obra que se tem em mãos, colocarmo-nos no papel de quem o escreveu e conseguir passar para o leitor um sentimento de interesse na leitura da mesma.

Ora, no caso de hoje, esse desafio é ainda maior, porquanto, o livro aqui presente, cujo título é A gestão da doença no espaço sociocultural

* Texto da apresentação pública da obra de Fátima Viegas, A gestão da doença no espaço sociocultural e urbano de Luanda: os curandeiros tradicionais e os neotradicionais (Prefácio de Ramon Sarró. Luanda, Editorial Kilombelombe [«Ciências Humanas e Sociais. Série Sociologia e Antropologia»; 8], 2015, 402p.), efectuada no anfiteatro principal da Faculdade de Ciências Sociais (FCS) da Universidade Agostinho Neto (UAN), em Luanda, por ocasião das comemorações do Dia da África, 25 de Maio de 2015.

** Professor Associado da Faculdade de Direito (FD) da Universidade Agostinho Neto (UAN) e Director do Centro de Estudos Jurídicos, Económicos e Sociais da UAN. 
e urbano de Luanda: Os curandeiros tradicionais e os neotradicionais, escrito pela Professora Doutora Fátima Viegas, trata-se de um compêndio (palavra já quase em desuso) de uma matéria muito complexa, mas profundamente atraente e inquietante para quem gosta de encontrar dúvidas, ter soluções que outras dúvidas trazem e, por sua vez, encontrar novas dúvidas.

No meu caso pessoal, por razões de profissão, mas também por razões de afecto, respeito, carinho pessoal e intelectual, no meu percurso encontrei sempre este cenário na convivência com a Professora Fátima Viegas, o que colocou em mim um peso de responsabilidade muito grande quando fui convidado para aqui vir tecer estas humildes palavras.

Mas como pedidos verdadeiros de amigos verdadeiros não se negam, não pude, também eu, negar.

Posto isto, cabe-me dizer que estamos perante um compêndio de Sociologia das Religiões, composto por cinco capítulos, todos eles muito densos de conteúdo, mas também muito bem interligados do ponto de vista de argumentos, o que facilita a leitura, sem que nos deixe de ser obrigatório a leitura, atenta, de cada uma das partes, para melhor entendimento da parte seguinte.

Não é um livro fácil, nem o podia ser, afinal trata de temas difíceis, prática a que a Professora Fátima Viegas já nos habituou. O tema do livro e a proposta da Professora Fátima Viegas tem como hipóteses de trabalho quatro possibilidades.

A primeira, em que se aponta para o facto de que em Angola, a fragilidade e a incapacidade do quadro nacional de saúde pública, proporciona a expansão de outras práticas médicas bastante procuradas por uma parte dos grupos sociais, não só nos meios rurais, mas também nos contextos urbanos.

A segunda, sobre o empenhamento das igrejas de cura, prestado à comunidade, apresentando-se quer como uma estratégia de poder dos neo-tradicionais, quer como uma expressão do mecanismo de redes de solidariedade e de formas de emancipação social.

A terceira, a coexistência das intermedicinas na sociedade angolana constituindo uma prática de facto e não de jure, porque o Estado aceita tacitamente a medicina tradicional e as práticas de cura espiritual, mas estas não estão articuladas no sistema nacional de saúde.

A quarta hipótese, vai no sentido da medicina tradicional e as suas práticas de cura dos neo-tradicionais constituírem uma continuidade, pois quer uma quer outra partilham o mesmo substrato cultural e 
simbólico e visam a superação dos desequilíbrios psicossomáticos do indivíduo e a sua reintegração social.

Estas quatro hipóteses, para além de se alinharem todas, constituem o fio condutor deste compêndio, com a particularidade de que mais do que um exercício teórico - já que se trata de uma Tese de Mestrado -, não se trata de um mero conglomerado de informação bibliográfica. Não!...

O estudo sustenta-se num longo e profundo trabalho de campo com entrevistas articuladas onde o sujeito coloca de forma aberta o que pensa, restando ao pesquisador articular o exposto para melhor percepção.

O tema em si tem o condão de poder ter muitas e variadas abordagens dependendo do lugar em que nós leitores ou melhor nós cidadãos nos colocarmos perante o fenómeno da religiosidade, da doença, da cura, da crença, da espiritualidade, enfim, de todas essas dimensões que por vezes são tratadas e vistas com uma demasiada leveza, nos tempos que correm.

Ou são vistas como temas de fatalidade sem que se procurem razões não fundamentadas para as suas práticas, ou ainda, como fazendo parte de um saco grande sem fundo a que se dá o nome de Cultura quando sobretudo se quer justificar o injustificável.

Ora a Professora Fátima Viegas não escolheu nenhum destes caminhos, optou mesmo por fazer um caminho novo procurando conciliar posições entre a medicina tradicional e a medicina convencional, desmistificando as propostas que a coberto de serem braços de uma medicina tradicional, se afiguram como complicadores e veículos de burla junto dos cidadãos, negociando, muitas vezes, a fé alheia para fins inconfessos.

Procurou, como bem finaliza nas conclusões da obra, colocar um desafio para se encontrar uma nova perspectiva global contra hegemónica no campo da saúde, entre racionalidades científicas e o senso comum mergulhado na sabedoria africana, que desempenham um lugar importante na gestão da doença e da cura da maioria da população angolana. Isso mesmo só é possível se cada um dos intervenientes nestes processos fizer, com humildade e objectividade, a sua parte.

Neste sentido fica também um alerta a navegação ao poder político para que tenha uma intervenção regulatória que leve em conta a realidade sociológica angolana, com vista a criação de bem estar, desenvolvimento e harmonia. 
Guardei para o final algumas palavras sobre a autora.

A Professora Fátima Viegas, pesquisadora sénior, coloca hoje no mercado uma obra cujas referências estão plasmadas na nossa sociedade e que ela teve o condão de na sua prática diária resgatar entre ou com várias instâncias as motivações, implicações e certezas sobre este tema tão candente.

Fê-lo a partir do seu quotidiano, como uma verdadeira «operária da sociologia religiosa» e fê-lo com mérito, o que só é possível quando se empresta humildade, amor e confiança naquilo que se faz.

Muito obrigado Professora Fátima Viegas minha amiga, colega de profissão e irmã por minha opção, ficamos-te muito gratos por nos brindares a nós aqui presentes e Angola, neste ano dos nossos 40 anos de independência com esse Compêndio de Sociologia Religiosa.

Um última palavra de parabéns a Editorial Kilombelombe, pelo rico trabalho editorial que tem feito na área das ciências sociais e não só.

\section{José Octávio Serra Van-Dúnem}

É Professor associado com agregação na Faculdade de Direito da Universidade Agostinho Neto (UAN), onde lecciona a cadeira de Filosofia do Direito e diversos cursos na especialidade de Sociologia ética e responsabilidade corporativa. Tem igualmente leccionado em diversos cursos de pós-graduação no Centro de Estudos Jurídicos, Económicos e Sociais (CEJES) da Faculdade de Direito da uAN, e é actualmente Professor convidado nas seguintes universidades: Universidade Católica de Angola (UCAN), Universidade Nova de Lisboa (Lisboa, Portugal), Universidade de Pelotas (Brasil) e Universidade Federal do Rio Grande do Sul (Brasil).

É doutorado em Ciências Humanas, com especialidade em Sociologia (2003), pelo Instituto Universitário de Pesquisas do Rio de Janeiro (IUPERJ), Universidade Cândido Mendes/Universidade Estadual do Rio de Janeiro (Brasil); possui um Mestrado em Ciências Humanas, com especialidade em Sociologia (1999), pelo IUPERJ, Universidade Cândido Mendes/Universidade Estadual do Rio de Janeiro (Brasil). É licenciado em Filosofia (1988) pela Faculdade de Ciências Humanas da Universidade Católica Portuguesa (Lisboa). É pós-graduado em Língua e Cultura Portuguesa (1989) pela Faculdade de Letras da Universidade Católica Portuguesa; pós-graduado em Ciências da Educação (1989) pela Faculdade de Letras da Universidade Católica Portuguesa; pós-graduado em Prévision et prospective démografique (1996) pelo Institute de Demographie de l'Université Catholique de 
Louvain (Bélgica), etc. É coordenador do curso de pós-graduação em Direito de petróleo e gás da Faculdade de Direito da UAN. Foi vice-decano da Faculdade de Direito da uAn (2003-2004) e Decano da mesma faculdade (2005-2009). As suas áreas de interesse são: Filosofia do Direito, Sociologia, Ética e responsabilidade social, Direito do petróleo e gás, governança corporativa, História e sociologia da ciência. Além de inúmeros artigos em revistas especializadas e textos em livros colectivos, publicou a obra Fundos sociais: Um colírio no combate à pobreza? Um estudo de caso do Fundo de Apoio Social no Município de Viana - Angola (Prefácio de Luiz António Machado da Silva, Luanda, Kilombelombe, 2008, 320p. [«Ciências Humanas e Sociais: série Sociologia e Antropologia; 2]).

[e-mail: otdunem@gmail.com] 